\title{
Inflammatory Markers and MicroRNAs: The Backstage Actors Influencing Prognosis in Colorectal Cancer Patients
}

\author{
Rihab Nasr ${ }^{\dagger}$, Miza Salim Hammoud ${ }^{\dagger}$, Farah Nassar, Deborah Mukherji, Ali Shamseddine and \\ Sally Temraz * \\ Department of Internal Medicine, American University of Beirut Medical Center, Riad El Solh, \\ Beirut 110 72020, Lebanon; rn03@aub.edu.lb (R.N.); ms302@aub.edu.lb (M.S.H.); fn17@aub.edu.lb (F.N.); \\ dm25@aub.edu.lb (D.M.); as04@aub.edu.lb (A.S.) \\ * Correspondence: st29@aub.edu.lb; Tel.: +961-1-374374 \\ t These authors contributed equally to this work.
}

Received: 31 May 2018; Accepted: 25 June 2018; Published: 26 June 2018

\begin{abstract}
Background: Colorectal cancer (CRC) remains a deadly disease, afflicting the lives of millions worldwide. The prognosis of CRC patients is best predicted by surgical resection and pathological analysis of specimens. Emerging evidence has attributed a significant role to inflammatory markers and microRNAs (miRNAs) in the prognosis and survival of CRC patients. Aim: Here, we review the literature on inflammatory markers and miRNAs with an established role on survival rates, response to systemic chemotherapy, and other clinic-pathological parameters in CRC patients. Results: Our literature review revealed a critical role of inflammatory markers-specifically, the acute-phase proteins, inflammatory cytokines, and blood cell ratios-on prognostic outcomes in CRC patients. MiRNAs, on the other hand, were useful in predicting prognosis and clinical response and accordingly stratifying CRC patients for optimal drug selection. Conclusion: These biomarkers are easily measured in routine blood exams and can be used in adjunct to the tumor-node-metastasis (TNM) staging system to identify high-risk patients and those who are more likely to benefit from chemotherapy and other targeted therapies. However, more prospective studies are needed for the validation of these discussed prognostic and predictive biomarkers.
\end{abstract}

Keywords: colorectal cancer; microRNA; inflammatory markers; prognosis; survival outcomes

\section{Introduction}

Worldwide, colorectal cancer (CRC) remains one of the main causes of cancer death, with an incidence approaching over 1.4 million annually [1]. Survival among patients with stage II CRC approaches $70-80 \%$; however, around $30 \%$ will relapse. Still, there is no reliable biomarker to determine which stage II patients are at high risk and which should be managed with adjuvant chemotherapy. As for advanced stages III and IV, there is also a lack of reliable prognostic biomarkers that determine which patients will benefit from chemotherapy. In both early and advanced stages of the disease, identification of biomarkers that would improve CRC prognostication is required for better clinical management.

There is growing evidence that inflammation is involved in tumor etiology and that the ongoing systemic inflammatory response is associated with worse prognosis in numerous cancers [2]. Consequently, many studies have investigated the predictive and prognostic role of various inflammatory markers, such as c-reactive protein (CRP), albumin, haptoglobin, d-dimer, ferritin, fibrinogen, neutrophil-lymphocyte ratio, lymphocyte-monocyte ratio, and platelet-lymphocyte ratio [3-8], on response and survival outcomes in the setting of CRC. 
MicroRNAs (miRNAs) are small, noncoding, single-stranded RNA molecules with crucial regulatory functions, including proliferation, apoptosis, angiogenesis, and immune response [9]. Recent studies have described the role of miRNA expression in the initiation and progression of CRC and its response to different therapeutic strategies [10]. Thus, miRNAs can also be used as prognostic and predictive factors in the clinical setting of CRC in adjunct to the use of TNM stage, tumor grade, and tumor classification.

Here, we review the literature on inflammatory markers and miRNAs with an established role on survival rates, response to systemic chemotherapy, and other clinic-pathological parameters in CRC patients.

\section{Literature Review}

\subsection{Inflammatory Pathway}

Cancer represents a state of high physiological stress, with tumor hypoxia/necrosis and local tissue damage. In order to counteract these changes, the body responds with a systemic release of proinflammatory cytokines and growth factors [11]. Figure 1 summarizes the inflammatory processes discussed below. Several proinflammatory cytokines have been shown to regulate cancer cell growth and thereby contribute to tumor promotion and progression. Interleukin-6 (IL-6) and tumor necrosis factor- $\alpha$ (TNF- $\alpha$ ) are two cytokines which induce and maintain a systemic, low-grade inflammatory state [12,13]. IL-6 is primarily produced by monocytes and macrophages during acute inflammation and by T cells during chronic inflammation [14]. IL-6 binds to its receptor IL-6R and activates the signal transducer and activator transcription 3 (STAT3) pathway. A homodimer of phosphorylated STAT3 then translocates to the nucleus and induces the transcription of several target genes, promoting proliferation, cell growth, and the inhibition of apoptosis [15]. IL- 6 and TNF- $\alpha$ also trigger the nuclear factor $\mathrm{KB}(\mathrm{NF}-\mathrm{kB})$ cascade, thereby promoting the proliferation of cancer cells and rescuing the cancer cells from cell death [16]. Moreover, both signaling pathways increase enterocyte-specific nuclear localization of $\beta$-catenin, which contributes to colorectal cancer carcinogenesis [17].

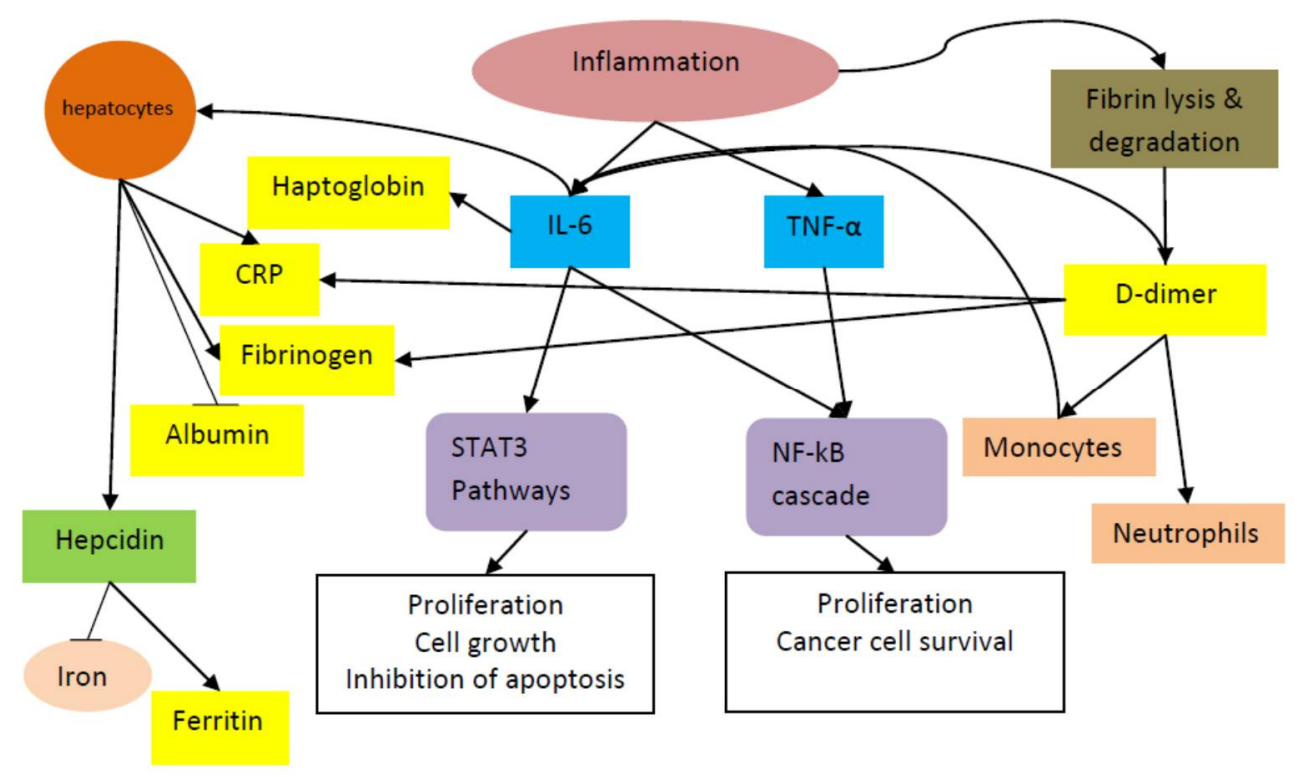

Figure 1. Inflammatory pathway involving inflammatory cytokines (shown in blue boxes) and acute-phase reactants (shown in yellow boxes). Only albumin is a negative acute-phase reactant, whose levels are reduced during inflammation (indicated by a bar instead of an arrow). STAT3: signal transducer and activator transcription 3 ; NF- $k \beta$ : nuclear factor $\kappa \beta$; TNF- $\alpha$ : tumor necrosis factor- $\alpha$; IL-6: interleukin-6; CRP: c-reactive protein. 
CRP, an acute-phase plasma protein, is generated from hepatocytes in response to inflammatory cytokines, such as IL-1, TNF- $\alpha$, and, in particular, IL-6 [18,19]. As part of the acute-phase response due to mild chronic inflammation associated with cancer, there is also a reduction in synthesis and an increase in degradation of albumin that results in hypoalbuminemia, whereas acute reduction in albumin concentrations in severe inflammations, such as burn and surgical trauma, is attributable to redistribution of albumin particles [20]. The end result is the nutritional and functional decline of patients, specifically those with advanced cancer. Haptoglobin is an acute-phase glycoprotein which is also produced in response to IL-6 [21]. Significantly elevated serum haptoglobin levels are seen in several types of cancers, including lung [22], breast [23], ovarian [24], and oral squamous cell cancers [25]. Haptoglobin contributes to increased oxidative stress and low-grade chronic inflammation [26].

D-dimer, a fibrin cleavage product, is a clinical marker that is used to diagnose pulmonary embolism [2]. D-dimer has been shown to have diverse effects on inflammatory processes and acute-phase responses, including neutrophil and monocyte activation; secretion of cytokines, including IL-6 and IL-1; and hepatic synthesis of acute-phase proteins, including fibrinogen and CRP [27,28]. Fibrinogen may enhance tumor cell proliferation, migration, and signaling through interaction with multiple integrin and non-integrin receptors and may also promote tumor angiogenesis by cooperation with growth factors, such as vascular endothelial growth factor and fibroblast growth factors [29].

In addition to its effect on acute-phase proteins, IL-6 induces the production of hepcidin by hepatocytes. Hepcidin in turn blocks iron release from macrophages, increases ferritin levels, and lowers transferrin saturation levels [30]. Ferritin, measured in routine blood examinations, is the primary iron-binding protein that exists both intracellularly and extracellularly [31]. Evidence has indicated that ferritin may play a role in cancer proliferation and immunosuppression, as well as therapeutic resistance [31].

\subsubsection{Acute-Phase Reactants}

Multiple studies have evaluated the role of acute-phase reactants, including albumin, CRP, ferritin, fibrinogen, haptoglobin, and D-dimer, on prognosis in both early and advanced CRCs. Table 1 summarizes the studies that were conducted on these markers in CRC. The role of pretreatment serum albumin as a prognostic tool was demonstrated by two studies. The first concluded that baseline serum albumin inversely correlated with tumor-node-metastasis (TNM) stages [32], and the second demonstrated that serum albumin levels may be used to linearly predict the postoperative morbidity and mortality among resectable CRCs [33]. CRP was studied extensively in the setting of CRC. Studies have highlighted the potential impact of elevated CRP levels on worse progression free survival (PFS) [34] and overall survival (OS) $[35,36]$ in metastatic CRC (mCRC) patients on palliative chemotherapy and best supportive care [37]. CRP was also found to be a strong prognostic factor of survival following resection of colorectal liver metastases [38]. Moreover, in CRC patients undergoing surgical resection, higher CRP levels correlated with worse disease free survival (DFS) [39], increased anastomotic leak, and increased mortality [40]. An elevated CRP-to-albumin ratio was also predictive of worse survival in mCRC patients [41] and CRC surgery patients [42]. These results suggest that CRP levels should be taken into consideration when selecting treatment regimens for patients with CRC.

Two studies evaluated the prognostic impact of ferritin in CRC. Both studies showed that high ferritin levels were associated with poor survival in both resectable CRC [31] and mCRCs [43]. It is worth noting that when stratified by TNM stages, ferritin levels remained statistically significant with only stage III patients [31]. Haptoglobin, on the other hand, was also associated with poor survival. Moreover, high serum haptoglobin levels were significantly increased in the CRC-distant metastasis (CRC-M1) group compared to the CRC-no metastasis (CRC-M0) group. The study further demonstrated that, combined with serum carbohydrate antigen 19-9 (CA19-9) levels and serum carcinoembryonic antigen (CEA) levels, serum haptoglobin levels accurately predicted CRC liver metastasis [6]. Also, high pretreatment D-dimer levels were shown to predict poor survival in 
CRC [44]. D-dimer levels were significantly increased in poorly differentiated tumors, specifically in more poorly differentiated tumors with a higher T stage [45]. Data on preoperative fibrinogen, however, was not conclusive. One retrospective study correlated preoperative fibrinogen with cancer severity indicators, such as presence of systemic metastasis $(p<0.001)$, depth of tumor invasion pT $(p<0.001)$, node involvement $\mathrm{pN}(p=0.001)$, and CEA serum level $(p<0.001)$, but it did not predict patient prognosis after colorectal cancer surgery [46]. Another study revealed that elevated preoperative plasma fibrinogen levels correlated significantly with venous invasion, advanced stage, and postoperative distant metastases, but not with lymph node involvement [47]. The study also showed an independent association between elevated preoperative plasma fibrinogen levels and impaired OS in patients with colorectal cancer in a multivariate survival analysis [47].

Table 1. Studies evaluating the prognostic impact of acute phase proteins in colorectal cancer (CRC).

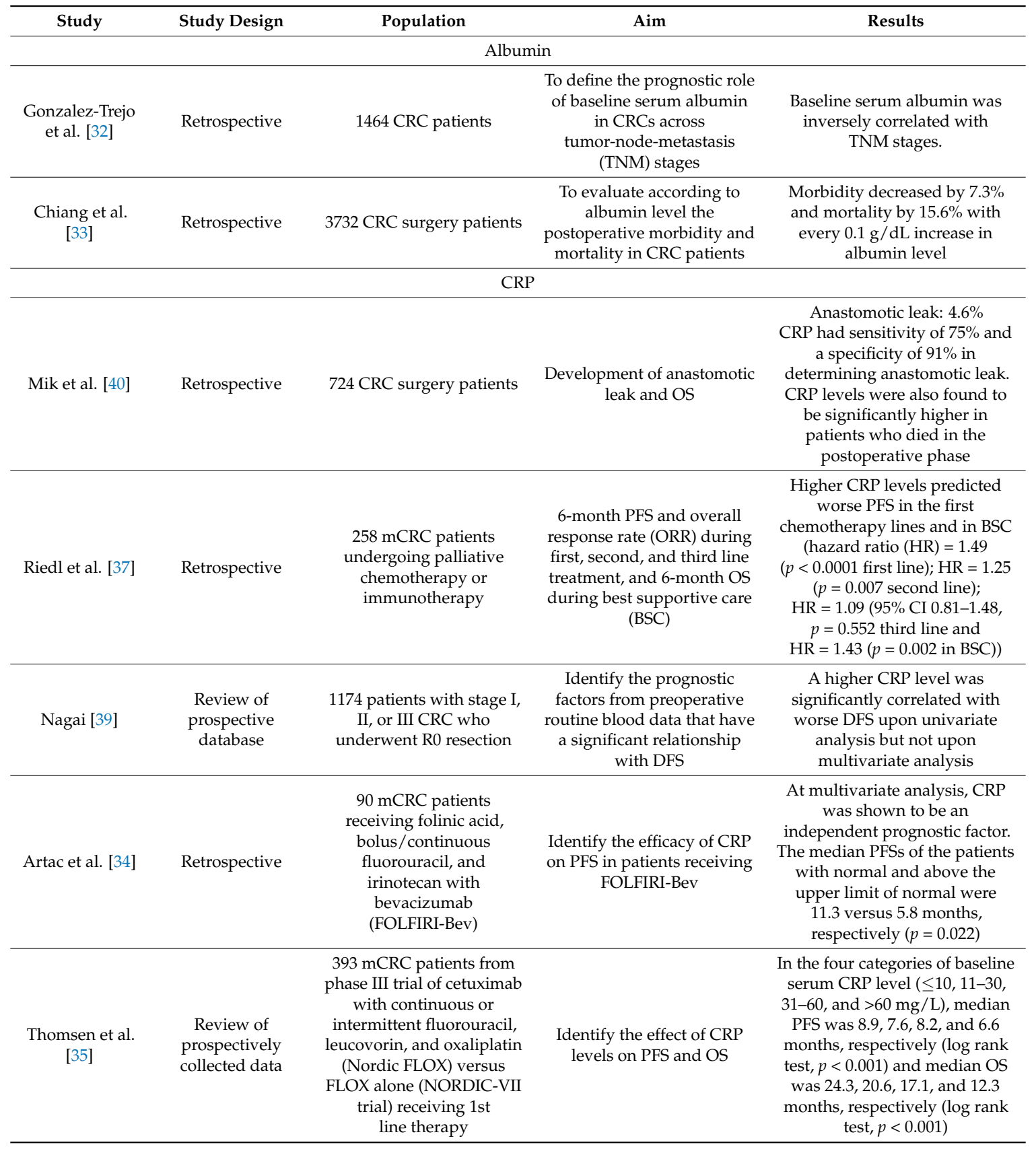


Table 1. Cont.

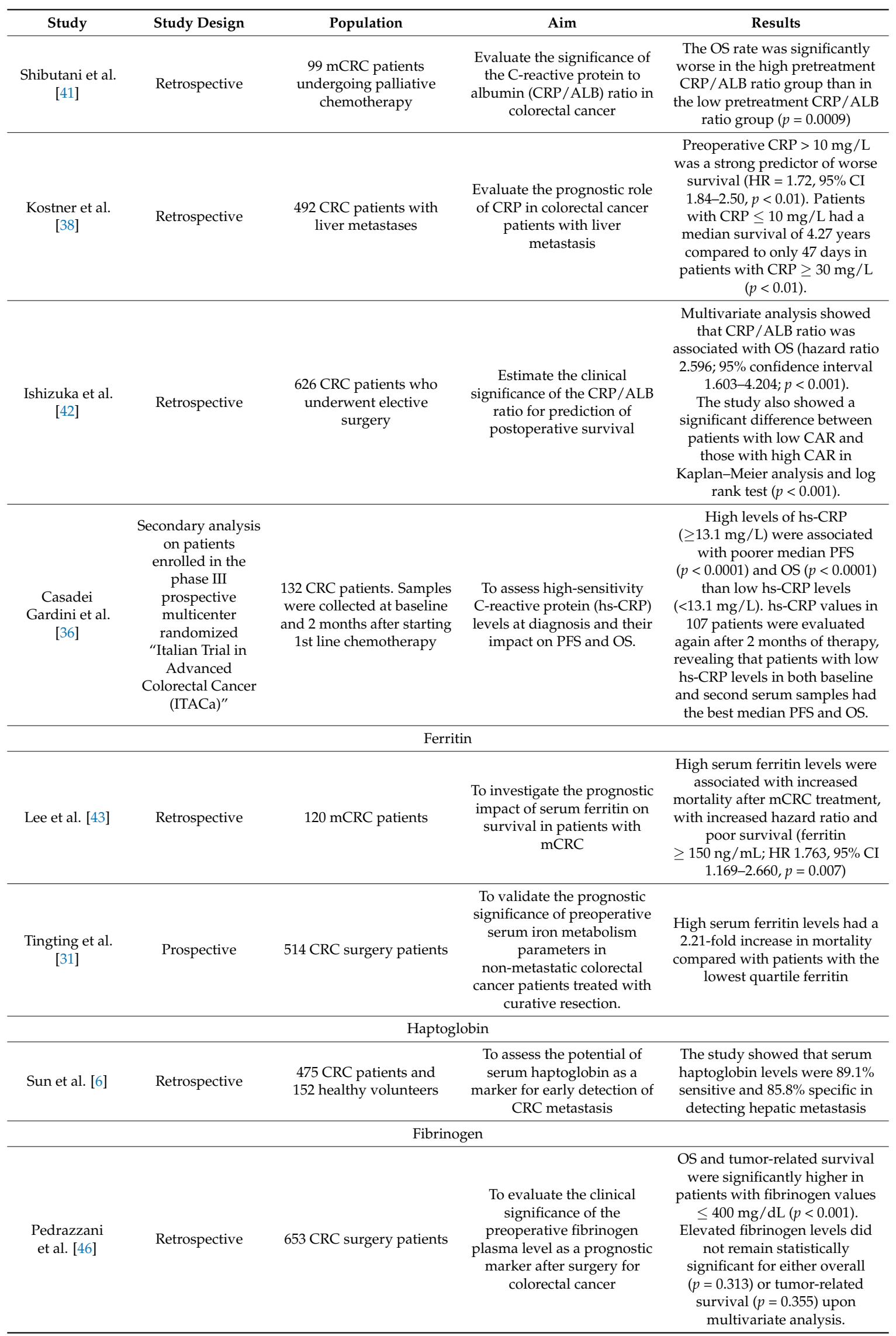


Table 1. Cont.

\begin{tabular}{|c|c|c|c|c|}
\hline Study & Study Design & Population & Aim & Results \\
\hline \multicolumn{5}{|c|}{ D-dimer } \\
\hline Lu et al. [44] & $\begin{array}{l}\text { Meta-analysis of } \\
15 \text { studies }\end{array}$ & 2283 CRC patients & $\begin{array}{l}\text { To provide insight into the } \\
\text { prognostic role of } \\
\text { pretreatment D-dimer levels }\end{array}$ & $\begin{array}{c}\text { High pretreatment plasma } \\
\text { D-dimer predicts poor survival } \\
\text { of CRC HR of } 2.167(95 \% \text { CI: } \\
1.672-2.809, p<0.001)\end{array}$ \\
\hline $\begin{array}{l}\text { Tekesin et al. } \\
\text { [45] }\end{array}$ & Prospective study & 165 CRC surgery patients & $\begin{array}{l}\text { To relate the preoperative } \\
\text { D-dimer and CEA levels of } \\
\text { patients with CRC } \\
\text { undergoing surgical } \\
\text { resection to the prognosis } \\
\text { and postoperative } \\
\text { survival rate }\end{array}$ & $\begin{array}{l}\text { Increased D-dimer and CEA } \\
\text { levels were associated with } \\
\text { significant decrease in } \\
\text { postoperative survival rate } \\
\text { and prognosis }\end{array}$ \\
\hline
\end{tabular}

\subsubsection{Inflammatory Cytokines}

Interleukins are a type of cytokine that control growth and differentiation, cell migration, and inflammatory and anti-inflammatory responses by the immune system [49]. Several proinflammatory interleukins have been implicated in CRC. In patients undergoing surgery, IL-6 levels were higher in stage II CRC patients than in stage III patients. IL-6 levels were found to be positively correlated with CRP and CEA levels, as well as with pT4 stage disease. Also, IL-6 was significantly associated with OS in all stages of CRC, but DFS was significantly different only in the stage II disease group [50]. Pretreatment serum concentrations of IL- $1 \beta$ and IL-6, as well as TNF- $\alpha$, predicted PFS regardless of CRP levels. Measurement of IL-1 $\beta$ and IL- 6 may help identify early cancer progression among patients with CRP $<5 \mathrm{mg} / \mathrm{L}$ in routine practice [51]. IL-37, which is highly abundant in healthy tissue adjacent to malignant tissue, suppressed cell migration, invasion, proliferation, colony formation, and cancer stem cells through suppressing $\beta$-catenin. Thus, the lower the expression of IL-37, the more highly malignant the CRC seems to be. In fact, IL-37 levels were found to be independent prognostic factors of OS and PFS in CRC patients [52]. High IL-23 expression was associated with advanced pathological T stage $(p<0.001)$ and late TNM stage $(p<0.003)$. Elevated serum IL-23 levels were also associated with poor 5-year PFS and OS ( $p<0.048$ and $p<0.028$, respectively). The study showed that high IL-23 expression was predominant during advanced invasion and late-stage CRC [53]. IL-17 levels, on the other hand, were not predictive of unfavorable clinical outcomes, but they correlated with CD8 and CD16 cell invasion, which, by themselves, are predictors of unfavorable outcomes [54].

TNF- $\alpha$ is known to activate NF-k $\beta$ to protect tumor cells, and its upregulation leads to resistance to apoptosis and induces drug resistance in certain cancers [55]. Nevertheless, their expression and prognostic role in CRC remains unclear [56]. In CRC patients who had undergone surgery for their primary cancer, the higher levels of TNF- $\alpha$ were specifically associated with CRC-specific mortality [57]. Also, TNF- $\alpha$ expression in surgically resectable CRCs was associated with differentiation $(p=0.019)$, TNM stage $(p=0.039)$, lymph nodes metastasis $(p=0.024)$, and lymph vascular invasion $(p=0.027)$. TNF- $\alpha$ levels were also associated with decreased DFS $(p=0.0209)$ and OS $(p=0.0163)$ [56]. Another study reported that cytokine levels and the CRP level are clinically relevant for CRC progression, and 
that measurement of TNF- $\alpha$ serum levels may help identify early cancer progression among patients with CRC [51].

\subsubsection{Blood Cell Ratios}

Several studies questioned the role of various blood cell ratios, such as neutrophil to lymphocyte ratio (NLR), lymphocyte to monocyte ratio (LMR), and platelet to lymphocyte ratio (PLR), in predicting the clinical outcomes of colorectal cancer.

NLR denotes the balance between the inflammatory response and the antitumor immune function. Tang et al. investigated the association of NLR and survival outcomes in colorectal cancer patients with liver metastasis. Their results demonstrated that elevated pretreatment NLR was significantly related to poor OS (HR 2.17, 95\% CI 1.82-2.58) and recurrence-free survival (HR 1.96, 95\% CI 1.64-2.35) [8]. Haram et al. had the same results with respect to OS, as their study results proved that high NLR is a negative predictive factor, not only in mCRC tumors, but also in locally advanced tumors [4]. Kim et al. also showed that high NLR $(\geq 3.0)$ is an independent risk factor predicting poor long-term outcomes in patients with stage III and IV, but not in stage I and II [58].

The prognostic significance of LMR was studied in multiple settings. In chemo-naïve mCRC, Lin et al. showed, using a sample size of 488 patients, that patients with high pre-chemotherapy LMR $(\geq 3.11)$ experienced significant improvement in PFS $(9.2$ vs. 7.6 months, $p<0.001)$ and OS (19.4 vs. 16.6 months, $p<0.001)$ compared with patients with low pre-chemotherapy LMR. These results were also seen in the setting of resectable CRC, as a recent study published in March 2017 showed an independence of LMR in being a predictive factor of survival [59]. The study had a huge sample size of 1623 with a cut-off value of LMR 2.38. They were able to show that low LMR $(<2.38)$ was associated with higher stage and grade of tumor, and more present in right-sided tumors. On the other hand, high LMR $(\geq 2.38)$ was present in early stages and grades of CRC, left-sided tumors and patients had a better OS $(p<0.001)$ independent of age, TNM stage, and grade [3]. The predictive value of LMR was also questioned in CRC cases metastatic to the liver and treated with radiofrequency ablation [7]. Median OS was 55 months in patients with LMR > 3.96 and 34 months in patients with $\operatorname{LMR} \leq 3.96(p=0.007)$. Time to recurrence (TTR) of metastatic lesions was 35 months in the group with LMR > 3.96 and 25 months in the other. Therefore, the study managed to support LMR being a novel predictor of outcomes in CRC [7].

A systematic review done by Tan et al. [60] included 15 studies and a total of 3991 CRC patients. The study analyzed the relationship between PLR and OS and DFS. The meta-analysis showed that elevated PLR was significantly associated with lower OS (pooled HR, 1.53; 95\% CI, 1.24-1.89; $p \leq 0.001$ ), DFS (pooled HR, 1.68; 95\% CI, 1.07-2.62; $p=0.023$ ), poor tumor differentiation (odds ratio (OR) 2.12; $95 \% \mathrm{CI}, 1.45-3.08, p<0.001)$ ), the propensity toward depth of infiltration (OR 1.69; 95\% CI, 1.20-2.39, $p=0.003)$, and recurrence (HR, 2.71;95\% CI, 1.31-5.60, $p=0.005)$. Therefore, the authors suggested that high peripheral blood PLR can be used as a predictor of OS and certain clinic pathological parameters in patients with CRC [60].

\subsection{MiRNAs}

During the recent years, it has become clear that aberrant miRNA expression has a functional role in CRC [10]. MiRNAs are evolutionarily conserved, single stranded, noncoding RNA molecules that bind target miRNAs and prevent their translation. Specific miRNAs can act as either tumor suppressors or oncogenes, depending on the cellular environment in which they are expressed [10]. MiRNAs have been found to be dysregulated in various types of cancers, including CRC, and their functions have been linked to many of the processes involved in tumorigenesis, from initiation to progression and metastasis [10]. Interestingly, a number of studies have described a correlation between the expression pattern of miRNAs and the diagnosis, prognosis [61], and therapeutic outcome in CRC [62-67]. These data suggest that miRNAs may be potential molecular classifiers, early detection biomarkers, and therapeutic targets for CRC [67]. An extraordinary advantage of miRNAs is represented by 
their presence in stable form in body fluids, including blood, making them promising noninvasive biomarkers. Accumulating data have indeed revealed that circulating miRNAs can serve as diagnostic, prognostic, and predictive biomarkers for CRC. In this review, we mainly focus on examples of miRNAs with potential prognostic and predictive value (summarized in Table 2).

Chen et al. revealed that high levels of serum miR-155 is associated with resistance to adjuvant chemotherapy mFOLFOX (5-fluorouracil, leucovorin, and oxaliplatin) [68]. Furthermore, elevated levels of circulating miR-155, together with miR-200c and miR-210, implicate local recurrence and distant metastasis [68]. Aberrant expression of serum miR-19a was shown to predict resistance to first line FOLFOX chemotherapy in advanced CRC patients. These results were concordant with a recent study showing that serum exosomal miR-19a was predictive of poor prognosis [64,65]. In addition to chemotherapy resistance, a study published in 2017 showed that postoperative plasma miR-31, miR-141, and miR-16 can be used as potential biomarkers for early prediction of disease recurrence following resection [61]. A recent meta-analysis published in 2018 also confirmed the prognostic value of circulating miR-141 in CRC [69]. Moreover, high expression of miR-126 was correlated with bevacizumab resistance in $\mathrm{mCRC}$ [66] and that of miR-345, with lack of response to third line cetuximab and irinotecan [67].

We have highlighted thus far in this review the role of inflammatory biomarkers and miRNAs in CRC prognosis. It is thus important to note that inflammatory pathways in CRC could be regulated by miRNAs [70,71]. For example, a modulatory role of miR-105 in TNF- $\alpha$-induced CRC metastasis was described by Shen et al. [72]. Moreover, miR-34a was shown to be a crucial regulator of IL6/STAT3 signaling in CRC [73].

In summary, the emerging role of miRNA as promising non-invasive prognostic and predictive biomarkers in CRC is paramount. However, despite this promise and because of the inconsistency and little reproducibility among the published studies assessing the role of miRNAs as biomarkers, their clinical use is still in early stages of development and, accordingly, more optimized research is still needed to strengthen their clinical value.

Table 2. miRNAs that influence CRC prognosis.

\begin{tabular}{ccc}
\hline miRNA & Predictive Role in CRC & Reference \\
\hline $\begin{array}{c}\text { miR-155, miR-200c } \\
\text { and miR-210 }\end{array}$ & Resistance to adjuvant chemotherapy mFOLFOX & Chen et al. [68] \\
\hline miR-19a & Local recurrence and distant metastasis & Chen et al. [68] \\
\hline $\begin{array}{c}\text { miR-31, miR-141, } \\
\text { and miR-16 }\end{array}$ & Resistance to first line FOLFOX & $\begin{array}{c}\text { Chen et al. and } \\
\text { miR-141 }\end{array}$ \\
\hline miR-126 & Prediction of disease recurrence following resection & Yuan et al. [61] \\
\hline miR-345 & Bevacizumab resistance & Gao et al. [69] \\
\hline
\end{tabular}

\section{Materials and Methods}

Retrieval of studies was performed through Medline on PubMed by using the following "meSH terms": Colorectal neoplasm, Inflammatory biomarkers, C-reactive protein, Albumin, Serum Ferritin, Fibrinogen, D-dimer, Haptoglobin, Tumor necrotic factor, and Interleukins. We also used "key words", as well as manual search across abstracts obtained for proper selection criteria. The key words mainly assisted in retrieving articles addressing the prognostic and predictive value of blood count ratios and miRNA in CRC.

- Selection criteria consisted of the following:

- English published papers 
- $\quad$ Published between 2008-2018

- Published in peer reviewed journals

- Papers assessing prognostic role of inflammatory markers and predictive miRNAs in different settings of colorectal cancer

\section{Conclusions}

Even though prognosis of CRC patients is currently predicted by surgical resection and pathological analysis of specimens, these methods are considered suboptimal. A growing body of literature has investigated laboratory markers as prognostic factors adjunct to pathological staging. Data from literature prove the hypothesis that systemic inflammation is the maestro of malignant cell evolution and tumor advancement. The change in the level of acute-phase reactants, such as CRP, ferritin, fibrinogen, D-dimer, haptoglobin, and albumin, was found to be associated with a dismal prognosis and survival outcome in colorectal cancer patients in various settings of the disease (summarized in Figure 2). Little is reported about the clinical use of these inflammatory biomarkers for CRC patients, so it would be interesting to study their sensitivity and specificity alone and combined in different cohorts. MicroRNA expression also showed a substantial correlation with the tumor biology and behavior, and mounting evidences suggest that aberrant miRNA expression can play a crucial role in CRC and can serve as potentially useful biomarkers for predicting prognosis and clinical response and accordingly stratify CRC patients for optimal drug selection. On the other hand, miRNAs have not been yet clinically utilized due to the inconsistency and poor reproducibility upon their detection in circulation. In order to overcome these challenges, an optimal strategy for miRNA detection, which focuses on the variability in the patients' characteristics, experimental design, as well as the isolation and detection methodologies, could be followed, as discussed in Nassr et al. [74]. As such, large-scale prospective studies are needed to validate these potential prognostic and predictive biomarkers, as well as to determine their levels, sensitivity, and specificity in CRC patients with different primary tumor locations.

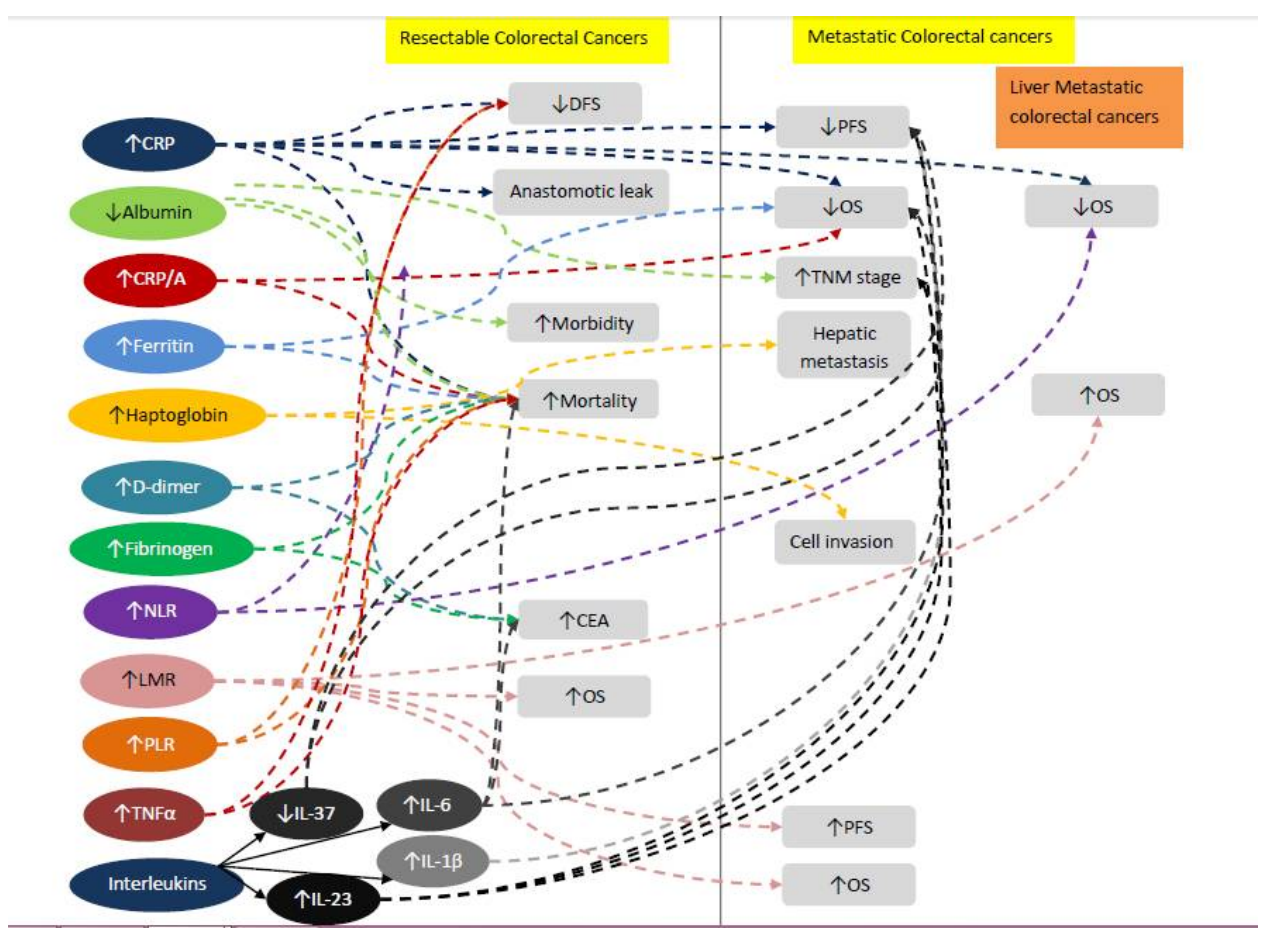

Figure 2. Current evidence correlating inflammatory biomarkers to survival and outcomes in resectable and metastatic colorectal cancers. NLR: neutrophil to lymphocyte ratio; LMR: lymphocyte to monocyte ratio; PLR: platelet to Lymphocyte ratio. 
Author Contributions: Conceptualization, R.N. and S.T.; Methodology, F.N. and M.S.H.; Data Curation, F.N. and M.S.; Writing-Original Draft Preparation, S.T. and R.N.; Writing-Review and Editing, D.M. and A.S.; Supervision, S.T.

Conflicts of Interest: The authors declare no conflict of interest.

\section{Abbreviations}

$\begin{array}{ll}\text { CRC } & \text { Colorectal cancer } \\ \text { CRP } & \text { C-reactive protein } \\ \text { TNF- } \alpha & \text { Tumor necrosis factor } \alpha \\ \text { IL } & \text { Interleukin } \\ \text { TNM } & \text { Tumor-node-metastasis } \\ \text { NLR } & \text { Neutrophil to lymphocyte ratio } \\ \text { LMR } & \text { Lymphocyte to monocyte ratio } \\ \text { PLR } & \text { Platelet to lymphocyte ratio } \\ \text { M0 } & \text { No metastasis } \\ \text { M1 } & \text { Distant metastasis } \\ \text { FOLFOX } & \text { 5-Fluorouracil, leucovorin, and oxaliplatin } \\ \text { CA19-9 } & \text { Carbohydrate antigen 19-9 } \\ \text { CEA } & \text { Carcinoembryonic antigen } \\ \text { OS } & \text { Overall survival } \\ \text { PFS } & \text { Progression free survival } \\ \text { DFS } & \text { Disease free survival } \\ \text { ORR } & \text { Overall response rate } \\ \text { HR } & \text { Hazard ratio } \\ \text { FOLFIRI } & \text { Folinic acid, bolus/continuous fluorouracil, and irinotecan } \\ \text { Bev } & \text { Bevacizumab }\end{array}$

\section{References}

1. Ferlay, J.; Soerjomataram, I.; Dikshit, R.; Eser, S.; Mathers, C.; Rebelo, M.; Parkin, D.M.; Forman, D.; Bray, F. Cancer incidence and mortality worldwide: Sources, methods and major patterns in GLOBOCAN 2012. Int. J. Cancer 2015, 136, E359-E386. [CrossRef] [PubMed]

2. Pulivarthi, S.; Gurram, M.K. Effectiveness of d-dimer as a screening test for venous thromboembolism: An update. N. Am. J. Med. Sci. 2014, 6, 491-499. [PubMed]

3. Chan, J.C.; Chan, D.L.; Diakos, C.I.; Engel, A.; Pavlakis, N.; Gill, A.; Clarke, S.J. The lymphocyte-to-monocyte ratio is a superior predictor of overall survival in comparison to established biomarkers of resectable colorectal cancer. Ann. Surg. 2017, 265, 539-546. [CrossRef] [PubMed]

4. Haram, A.; Boland, M.R.; Kelly, M.E.; Bolger, J.C.; Waldron, R.M.; Kerin, M.J. The prognostic value of neutrophil-to-lymphocyte ratio in colorectal cancer: A systematic review. J. Surg. Oncol. 2017, 115, 470-479. [CrossRef] [PubMed]

5. Iversen, L.H.; Thorlacius-Ussing, O. Relationship of coagulation test abnormalities to tumour burden and postoperative DVT in resected colorectal cancer. Thromb. Haemost. 2002, 87, 402-408. [PubMed]

6. Sun, L.; Hu, S.; Yu, L.; Guo, C.; Sun, L.; Yang, Z.; Qi, J.; Ran, Y. Serum haptoglobin as a novel molecular biomarker predicting colorectal cancer hepatic metastasis. Int. J. Cancer 2016, 138, 2724-2731. [CrossRef] [PubMed]

7. Facciorusso, A.; Del Prete, V.; Crucinio, N.; Serviddio, G.; Vendemiale, G.; Muscatiello, N. Lymphocyte-to-monocyte ratio predicts survival after radiofrequency ablation for colorectal liver metastases. World J. Gastroenterol. 2016, 22, 4211-4218. [CrossRef] [PubMed]

8. Tang, H.; Li, B.; Zhang, A.; Lu, W.; Xiang, C.; Dong, J. Prognostic significance of neutrophil-to-lymphocyte ratio in colorectal liver metastasis: A systematic review and meta-analysis. PLoS ONE 2016, 11. [CrossRef] [PubMed]

9. MacFarlane, L.-A.; Murphy, P.R. MicroRNA: Biogenesis, function and role in cancer. Curr. Genom. 2010, 11, 537-561. [CrossRef] [PubMed] 
10. Schetter, A.J.; Okayama, H.; Harris, C.C. The role of microRNAs in colorectal cancer. Cancer J. 2012, 18, 244-252. [CrossRef] [PubMed]

11. McMillan, D.C. Systemic inflammation, nutritional status and survival in patients with cancer. Curr. Opin. Clin. Nutr. Metab. Care 2009, 12, 223-226. [CrossRef] [PubMed]

12. Van Greevenbroek, M.M.; Schalkwijk, C.G.; Stehouwer, C.D. Obesity-associated low-grade inflammation in type 2 diabetes mellitus: Causes and consequences. Neth. J. Med. 2013, 71, 174-187. [PubMed]

13. Greenberg, A.S.; Obin, M.S. Obesity and the role of adipose tissue in inflammation and metabolism. Am. J. Clin. Nutr. 2006, 83, 461s-465s. [CrossRef] [PubMed]

14. Naugler, W.E.; Karin, M. The wolf in sheep's clothing: The role of interleukin-6 in immunity, inflammation and cancer. Trends Mol. Med. 2008, 14, 109-119. [CrossRef] [PubMed]

15. Waldner, M.J.; Foersch, S.; Neurath, M.F. Interleukin-6-A key regulator of colorectal Cancer development. Int. J. Biol. Sci. 2012, 8, 1248-1253. [CrossRef] [PubMed]

16. Hassanzadeh, P. Colorectal cancer and NF-кB signaling pathway. Gastroenterol. Hepatol. Bed Bench 2011, 4, 127-132. [PubMed]

17. Bollrath, J.; Phesse, T.J.; von Burstin, V.A.; Putoczki, T.; Bennecke, M.; Bateman, T.; Nebelsiek, T.; Lundgren-May, T.; Canli, O.; Schwitalla, S.; et al. gp130-mediated Stat3 activation in enterocytes regulates cell survival and cell-cycle progression during colitis-associated tumorigenesis. Cancer Cell 2009, 15, 91-102. [CrossRef] [PubMed]

18. Castell, J.V.; Gomez-Lechon, M.J.; David, M.; Fabra, R.; Trullenque, R.; Heinrich, P.C. Acute-phase response of human hepatocytes: Regulation of acute-phase protein synthesis by interleukin-6. Hepatology 1990, 12, 1179-1186. [CrossRef] [PubMed]

19. Zimmerman, M.A.; Selzman, C.H.; Cothren, C.; Sorensen, A.C.; Raeburn, C.D.; Harken, A.H. Diagnostic implications of C-reactive protein. Arch. Surg. 2003, 138, 220-224. [CrossRef] [PubMed]

20. Doweiko, J.P.; Nompleggi, D.J. The role of albumin in human physiology and pathophysiology, Part III: Albumin and disease states. JPEN 1991, 15, 476-483. [CrossRef] [PubMed]

21. Sadrzadeh, S.M.H.; Bozorgmehr, J. Haptoglobin phenotypes in health and disorders. Pathol. Patterns Rev. 2004, 121, 971S-1004S. [CrossRef]

22. Park, J.; Yang, J.S.; Jung, G.; Woo, H.I.; Park, H.-D.; Kim, J.-W.; Huh, W.; Ko, J.-W.; Kim, H.; Cho, J.-Y.; et al. Subunit-specific mass spectrometry method identifies haptoglobin subunit alpha as a diagnostic marker in non-small cell lung cancer. J. Proteom. 2013, 94, 302-310. [CrossRef] [PubMed]

23. Hamrita, B.; Chahed, K.; Trimeche, M.; Guillier, C.L.; Hammann, P.; Chaïeb, A.; Korbi, S.; Chouchane, L. Proteomics-based identification of $\alpha 1$-antitrypsin and haptoglobin precursors as novel serum markers in infiltrating ductal breast carcinomas. Clin. Chim. Acta 2009, 404, 111-118. [CrossRef] [PubMed]

24. Mandato, V.D.; Magnani, E.; Abrate, M.; Casali, B.; Nicoli, D.; Farnetti, E.; Formisano, D.; Pirillo, D.; Ciarlini, G.; Deiaco, P.; et al. Haptoglobin phenotype and epithelial ovarian cancer. Anticancer Res. 2012, 32, 4353-4358. [PubMed]

25. Lai, C.-H.; Chang, N.-W.; Lin, C.-F.; Lin, C.-D.; Lin, Y.-J.; Wan, L.; Sheu, J.J.-C.; Chen, S.-Y.; Huang, Y.-P.; Sing, Y.-T.; et al. Proteomics-based identification of haptoglobin as a novel plasma biomarker in oral squamous cell carcinoma. Clin. Chim. Acta 2010, 411, 984-991. [CrossRef] [PubMed]

26. Alvarez-Blasco, F.; Martinez-Garcia, M.A.; Luque-Ramirez, M.; Parraza, N.; San Millan, J.L.; Escobar-Morreale, H.F. Role of haptoglobin in polycystic ovary syndrome (PCOS), obesity and disorders of glucose tolerance in premenopausal women. PLoS ONE 2009, 4, e5606. [CrossRef] [PubMed]

27. Ritchie, D.G.; Levy, B.A.; Adams, M.A.; Fuller, G.M. Regulation of fibrinogen synthesis by plasmin-derived fragments of fibrinogen and fibrin: An indirect feedback pathway. Proc. Natl. Acad. Sci. USA 1982, 79, 1530-1534. [CrossRef] [PubMed]

28. Robson, S.C.; Shephard, E.G.; Kirsch, R.E. Fibrin degradation product D-dimer induces the synthesis and release of biologically active IL-1 beta, IL-6 and plasminogen activator inhibitors from monocytes in vitro. Br. J. Haematol. 1994, 86, 322-326. [CrossRef] [PubMed]

29. Sahni, A.; Simpson-Haidaris, P.J.; Sahni, S.K.; Vaday, G.G.; Francis, C.W. Fibrinogen synthesized by cancer cells augments the proliferative effect of fibroblast growth factor-2 (FGF-2). JTH 2008, 6, 176-183. [CrossRef] [PubMed] 
30. Macciò, A.; Madeddu, C.; Gramignano, G.; Mulas, C.; Tanca, L.; Cherchi, M.C.; Floris, C.; Omoto, I.; Barracca, A.; Ganz, T. The role of inflammation, iron, and nutritional status in cancer-related anemia: Results of a large, prospective, observational study. Haematologica 2015, 100, 124-132. [CrossRef] [PubMed]

31. Tingting, H.; Di, S.; Xiaoping, C.; Xiaohong, W.; Dong, H. High preoperative serum ferritin predicted poor prognosis in non-metastatic colorectal cancer. Saudi Med. J. 2017, 38, 268-275. [CrossRef] [PubMed]

32. Gonzalez-Trejo, S.; Carrillo, J.F.; Carmona-Herrera, D.D.; Baz-Gutierrez, P.; Herrera-Goepfert, R.; Nunez, G.; Ochoa-Carrillo, F.J.; Gallardo-Rincon, D.; Aiello-Crocifoglio, V.; Onate-Ocana, L.F. Baseline serum albumin and other common clinical markers are prognostic factors in colorectal carcinoma: A retrospective cohort study. Medicine 2017, 96, e6610. [CrossRef] [PubMed]

33. Chiang, J.M.; Chang, C.J.; Jiang, S.F.; Yeh, C.Y.; You, J.F.; Hsieh, P.S.; Huang, H.Y. Pre-operative serum albumin level substantially predicts post-operative morbidity and mortality among patients with colorectal cancer who undergo elective colectomy. Eur. J. Cancer Care 2017, 26. [CrossRef] [PubMed]

34. Artac, M.; Uysal, M.; Karaagac, M.; Korkmaz, L.; Er, Z.; Guler, T.; Boruban, M.C.; Bozcuk, H. Prognostic impact of neutrophil/lymphocyte ratio, platelet count, CRP, and albumin levels in metastatic colorectal cancer patients treated with folfiri-bevacizumab. J. Gastrointest. Cancer 2017, 48, 176-180. [CrossRef] [PubMed]

35. Thomsen, M.; Kersten, C.; Sorbye, H.; Skovlund, E.; Glimelius, B.; Pfeiffer, P.; Johansen, J.S.; Kure, E.H.; Ikdahl, T.; Tveit, K.M.; et al. Interleukin-6 and C-reactive protein as prognostic biomarkers in metastatic colorectal cancer. Oncotarget 2016, 7, 75013-75022. [CrossRef] [PubMed]

36. Casadei Gardini, A.; Carloni, S.; Scarpi, E.; Maltoni, P.; Dorizzi, R.M.; Passardi, A.; Frassineti, G.L.; Cortesi, P.; Giannini, M.B.; Marisi, G.; et al. Prognostic role of serum concentrations of high-sensitivity C-reactive protein in patients with metastatic colorectal cancer: Results from the ITACa trial. Oncotarget 2016, 7, 10193-10202. [PubMed]

37. Riedl, J.M.; Posch, F.; Moik, F.; Bezan, A.; Szkandera, J.; Smolle, M.A.; Kasparek, A.K.; Pichler, M.; Stoger, H.; Stotz, M.; et al. Inflammatory biomarkers in metastatic colorectal cancer: Prognostic and predictive role beyond the first line setting. Oncotarget 2017, 8, 96048-96061. [CrossRef] [PubMed]

38. Kostner, A.H.; Kersten, C.; Lowenmark, T.; Ydsten, K.A.; Peltonen, R.; Isoniemi, H.; Haglund, C.; Gunnarsson, U.; Isaksson, B. The prognostic role of systemic inflammation in patients undergoing resection of colorectal liver metastases: C-reactive protein (CRP) is a strong negative prognostic biomarker. J. Surg. Oncol. 2016, 114, 895-899. [CrossRef] [PubMed]

39. Nagai, H.; Yuasa, N.; Takeuchi, E.; Miyake, H.; Yoshioka, Y.; Miyata, K. The mean corpuscular volume as a prognostic factor for colorectal cancer. Surg. Today 2018, 48, 186-194. [CrossRef] [PubMed]

40. Mik, M.; Dziki, L.; Berut, M.; Trzcinski, R.; Dziki, A. Neutrophil to lymphocyte ratio and C-reactive protein as two predictive tools of anastomotic leak in colorectal cancer open surgery. Dig. Surg. 2018, 35, 77-84. [CrossRef] [PubMed]

41. Shibutani, M.; Maeda, K.; Nagahara, H.; Iseki, Y.; Hirakawa, K.; Ohira, M. The significance of the C-reactive protein to albumin ratio as a marker for predicting survival and monitoring chemotherapeutic effectiveness in patients with unresectable metastatic colorectal cancer. SpringerPlus 2016, 5, 1798. [CrossRef] [PubMed]

42. Ishizuka, M.; Nagata, H.; Takagi, K.; Iwasaki, Y.; Shibuya, N.; Kubota, K. Clinical significance of the C-reactive protein to albumin ratio for survival after surgery for colorectal cancer. Ann. Surg. Oncol. 2016, 23, 900-907. [CrossRef] [PubMed]

43. Lee, S.; Song, A.; Eo, W. Serum ferritin as a prognostic biomarker for survival in relapsed or refractory metastatic colorectal cancer. J. Cancer 2016, 7, 957-964. [CrossRef] [PubMed]

44. Lu, S.L.; Ye, Z.H.; Ling, T.; Liang, S.Y.; Li, H.; Tang, X.Z.; Xu, Y.S.; Tang, W.Z. High pretreatment plasma D-dimer predicts poor survival of colorectal cancer: Insight from a meta-analysis of observational studies. Oncotarget 2017, 8, 81186-81194. [CrossRef] [PubMed]

45. Tekesin, K.; Bayrak, S.; Esatoglu, V.; Ozdemir, E.; Ozel, L.; Melih Kara, V. D-dimer and carcinoembryonic antigen levels: Useful indicators for predicting the tumor stage and postoperative survival. Gastroenterol. Res. Pract. 2016, 2016. [CrossRef] [PubMed]

46. Pedrazzani, C.; Mantovani, G.; Salvagno, G.L.; Baldiotti, E.; Ruzzenente, A.; Iacono, C.; Lippi, G.; Guglielmi, A. Elevated fibrinogen plasma level is not an independent predictor of poor prognosis in a large cohort of Western patients undergoing surgery for colorectal cancer. World J. Gastroenterol. 2016, 22, 9994-10001. [CrossRef] [PubMed] 
47. Liang, T.; Kai, L.; Junfeng, W.; Cui, W.; Peng, Z.; Jianzhong, L. High preoperative plasma fibrinogen levels are associated with distant metastases and impaired prognosis after curative resection in patients with colorectal cancer. J. Surg. Oncol. 2010, 102, 428-432.

48. Yu, J.; Li, D.; Lei, D.; Yuan, F.; Pei, F.; Zhang, H.; Yu, A.; Wang, K.; Chen, H.; Chen, L.; et al. Tumor-specific D-dimer concentration ranges and influencing factors: A cross-sectional study. PLoS ONE 2016, 11, e0165390. [CrossRef] [PubMed]

49. Bondurant, K.L.; Lundgreen, A.; Herrick, J.S.; Kadlubar, S.; Wolff, R.K.; Slattery, M.L. Interleukin genes and associations with colon and rectal cancer risk and overall survival. Int. J. Cancer 2013, 132, 905-915. [CrossRef] [PubMed]

50. Shiga, K.; Hara, M.; Nagasaki, T.; Sato, T.; Takahashi, H.; Sato, M.; Takeyama, H. Preoperative serum interleukin-6 is a potential prognostic factor for colorectal cancer, including stage II patients. Gastroenterol. Res. Pract. 2016, 2016. [CrossRef] [PubMed]

51. Chang, P.H.; Pan, Y.P.; Fan, C.W.; Tseng, W.K.; Huang, J.S.; Wu, T.H.; Chou, W.C.; Wang, C.H.; Yeh, K.Y. Pretreatment serum interleukin-1beta, interleukin-6, and tumor necrosis factor-alpha levels predict the progression of colorectal cancer. Cancer Med. 2016, 5, 426-433. [CrossRef] [PubMed]

52. Yan, X.; Zhao, J.; Zhang, R. Interleukin-37 mediates the antitumor activity in colon cancer through beta-catenin suppression. Oncotarget 2017, 8, 49064-49075. [PubMed]

53. Hu, W.H.; Chen, H.H.; Yen, S.L.; Huang, H.Y.; Hsiao, C.C.; Chuang, J.H. Increased expression of interleukin-23 associated with progression of colorectal cancer. J. Surg. Oncol. 2017, 115, 208-212. [CrossRef] [PubMed]

54. Amicarella, F.; Muraro, M.G.; Hirt, C.; Cremonesi, E.; Padovan, E.; Mele, V.; Governa, V.; Han, J.; Huber, X.; Droeser, R.A.; et al. Dual role of tumour-infiltrating T helper 17 cells in human colorectal cancer. Gut 2017, 66, 692-704. [CrossRef] [PubMed]

55. Cusack, J.C.; Liu, R.; Baldwin, A.S. NF- $\kappa B$ and chemoresistance: Potentiation of cancer drugs via inhibition of NF- кB. Drug Resist. Updates 1999, 2, 271-273. [CrossRef] [PubMed]

56. Li, Y.; Jia, H.; Yu, W.; Xu, Y.; Li, X.; Li, Q.; Cai, S. Nomograms for predicting prognostic value of inflammatory biomarkers in colorectal cancer patients after radical resection. Int. J. Cancer 2016, 139, 220-231. [CrossRef] [PubMed]

57. Olsen, R.S.; Nijm, J.; Andersson, R.E.; Dimberg, J.; Wagsater, D. Circulating inflammatory factors associated with worse long-term prognosis in colorectal cancer. World J. Gastroenterol. 2017, 23, 6212-6219. [CrossRef] [PubMed]

58. Kim, J.H.; Lee, J.Y.; Kim, H.K.; Lee, J.W.; Jung, S.G.; Jung, K.; Kim, S.E.; Moon, W.; Park, M.I.; Park, S.J. Prognostic significance of the neutrophil-to-lymphocyte ratio and platelet-to-lymphocyte ratio in patients with stage III and IV colorectal cancer. World J. Gastroenterol. 2017, 23, 505-515. [CrossRef] [PubMed]

59. Nozoe, T.; Matono, R.; Ijichi, H.; Ohga, T.; Ezaki, T. Glasgow prognostic score (GPS) can be a useful indicator to determine prognosis of patients with colorectal carcinoma. Int. Surg. 2014, 99, 512-517. [CrossRef] [PubMed]

60. Tan, D.; Fu, Y.; Su, Q.; Wang, H. Prognostic role of platelet-lymphocyte ratio in colorectal cancer: A systematic review and meta-analysis. Medicine 2016, 95, e3837. [CrossRef] [PubMed]

61. Yuan, Z.; Baker, K.; Redman, M.W.; Wang, L.; Adams, S.V.; Yu, M.; Dickinson, B.; Makar, K.; Ulrich, N.; Bohm, J.; et al. Dynamic plasma microRNAs are biomarkers for prognosis and early detection of recurrence in colorectal cancer. Br. J. Cancer 2017. [CrossRef] [PubMed]

62. Deng, J.; Lei, W.; Fu, J.C.; Zhang, L.; Li, J.H.; Xiong, J.P. Targeting miR-21 enhances the sensitivity of human colon cancer HT-29 cells to chemoradiotherapy in vitro. Biochem. Biophys. Res. Commun. 2014, 443, 789-795. [CrossRef] [PubMed]

63. Peng, J.; Omran, A.; Ashhab, M.U.; Kong, H.; Gan, N.; He, F.; Yin, F. Expression patterns of miR-124, miR-134, miR-132, and miR-21 in an immature rat model and children with mesial temporal lobe epilepsy. J. Mol. Neurosci. 2013, 50, 291-297. [CrossRef] [PubMed]

64. Chen, Q.; Xia, H.-W.; Ge, X.-J.; Zhang, Y.-C.; Tang, Q.-L.; Bi, F. Serum miR-19a predicts resistance to FOLFOX chemotherapy in advanced colorectal cancer cases. Asian Pac. J. Cancer Prev. 2013, 14, 7421-7426. [CrossRef] [PubMed] 
65. Matsumura, T.; Sugimachi, K.; Iinuma, H.; Takahashi, Y.; Kurashige, J.; Sawada, G.; Ueda, M.; Uchi, R.; Ueo, H.; Takano, Y.; et al. Exosomal microRNA in serum is a novel biomarker of recurrence in human colorectal cancer. Br. J. Cancer 2015, 113, 275-281. [CrossRef] [PubMed]

66. Hansen, T.F.; Carlsen, A.L.; Heegaard, N.H.H.; Sørensen, F.B.; Jakobsen, A. Changes in circulating microRNA-126 during treatment with chemotherapy and bevacizumab predicts treatment response in patients with metastatic colorectal cancer. Br. J. Cancer 2015, 112, 624-629. [CrossRef] [PubMed]

67. Schou, J.V.; Rossi, S.; Jensen, B.V.; Nielsen, D.L.; Pfeiffer, P.; Høgdall, E.; Yilmaz, M.; Tejpar, S.; Delorenzi, M.; Kruhøffer, M. miR-345 in metastatic colorectal cancer: A non-invasive biomarker for clinical outcome in non-KRAS mutant patients treated with 3rd line cetuximab and irinotecan. PLoS ONE 2014, 9. [CrossRef] [PubMed]

68. Chen, J.; Wang, W.; Zhang, Y.; Chen, Y.; Hu, T. Predicting distant metastasis and chemoresistance using plasma miRNAs. Med. Oncol. 2013, 31, 799. [CrossRef] [PubMed]

69. Gao, S.; Zhao, Z.Y.; Wu, R.; Zhang, Y.; Zhang, Z.Y. Prognostic value of microRNAs in colorectal cancer: A meta-analysis. Cancer Manag. Res. 2018, 10, 907-929. [CrossRef] [PubMed]

70. Guo, Y.; Bao, Y.; Yang, W. Regulatory miRNAs in colorectal carcinogenesis and metastasis. Int. J. Mol. Sci. 2017, 18, 890. [CrossRef] [PubMed]

71. Josse, C.; Bours, V. MicroRNAs and inflammation in colorectal cancer. Adv. Exp. Med. Biol. 2016, 937, 53-69. [PubMed]

72. Shen, Z.; Zhou, R.; Liu, C.; Wang, Y.; Zhan, W.; Shao, Z.; Liu, J.; Zhang, F.; Xu, L.; Zhou, X.; et al. MicroRNA-105 is involved in TNF-alpha-related tumor microenvironment enhanced colorectal cancer progression. Cell Death Dis. 2017, 8. [CrossRef] [PubMed]

73. Rokavec, M.; Oner, M.G.; Li, H.; Jackstadt, R.; Jiang, L.; Lodygin, D.; Kaller, M.; Horst, D.; Ziegler, P.K.; Schwitalla, S.; et al. IL-6R/STAT3/miR-34a feedback loop promotes EMT-mediated colorectal cancer invasion and metastasis. J. Clin. Investig. 2014, 124, 1853-1867. [CrossRef] [PubMed]

74. Nassar, F.J.; Nasr, R.; Talhouk, R. MicroRNAs as biomarkers for early breast cancer diagnosis, prognosis and therapy prediction. Pharmacol. Ther. 2017, 172, 34-49. [CrossRef] [PubMed]

(C) 2018 by the authors. Licensee MDPI, Basel, Switzerland. This article is an open access article distributed under the terms and conditions of the Creative Commons Attribution (CC BY) license (http:/ / creativecommons.org/licenses/by/4.0/). 